\title{
Demigods of Technology Use - How Beating the Overconfidence Bias Can Prevent Medical Errors
}

\author{
Frederike Marie Oschinsky \\ University of Siegen \\ frederike.oschinsky@ \\ uni-siegen.de
}

\author{
Marius Mueller \\ University of Siegen \\ marius.mueller@uni-siegen.de
}

\author{
Bjoern Niehaves \\ University of Siegen \\ bjoern.niehaves@uni-siegen.de
}

\begin{abstract}
The healthcare domain faces considerable challenges due to the digitization of medical processes and routines. Information technologies are designed to enable physicians to treat more patients and to increase service quality and patient safety. Despite acknowledging the rapid digital transformation of healthcare, research often neglects whether physicians are actually able to effectively decide which technology to use in which setting and whether their technology use thus effectively enhances quality and safety. Literature on cognitive biases already looked broadly at related errors in judgment and action and questioned rational behavior. Nevertheless, overconfidence, being one of the most common cognitive biases, has barely been linked to the accurate adoption and use of technology by physicians. Against this background, this research-in-progress paper proposes a framework for conducting a mixed-methods study based on the particularities of overconfidence in healthcare. We invite future research to compare our approach with established theoretical frameworks in IS research.
\end{abstract}

\section{Introduction}

Up to 40 percent of annual deaths in the United States are preventable [6]. Lethal errors happen in roughly 6 percent of hospital admissions [8, 9]. Literature shows that most preventable deaths are caused by social determinants [e.g., 35, 36]. However, no less important and representing an emphasis of this research-in-progress paper, many medical flaws and treatment inaccuracies occur due to cognitive biases, because physicians are susceptible to errors in judgment and decision-making [e.g., 11, 49]. When medical practitioners are selective about what they pay attention to, distorted thinking and cognitive biases occur. In the digital age, that also applies to their adoption and use of information technology (IT).

A cognitive bias is an error in thinking, which results from the attempt to simplify information processing. It is defined as a systematic deviation from rationality, whereby inferences are drawn in an illogical fashion [30, 45, 2, 3, 27]. Cognitive biases are the reason why individuals often come up with divergent or even 'wrong' conclusions when processing and interpreting information about the world around them [25]. Although many cognitive biases serve an adaptive purpose as they allow to make sense of the world rather quickly, they often outplay well-considered but time-consuming decisions.

Information Systems (IS) research acknowledged that human decision-making is one decisive area of interest in the IS domain [23]. This seems to be especially true for action-oriented biases such as overconfidence [16]. Pressing issues such as privacy, trust, and security, fuel academic interest in this respect. Because the body of psychological knowledge often facilitates to advance the discipline and to provide valuable recommendations for practitioners [16], our study seeks to continue progressing on that path. There is a huge opportunity for combining IS research with behavioral economics principles such as cognitive biases to shed light on technology use and to inform design science research. In particular, the growing area of NeuroIS demonstrates potential to bring explanatory power to cognitive effects [13].

Against this background, it is surprising that cognitive biases received only limited attention in the technology-related healthcare domain [16]. The massive amount of information available to physicians at the point they have to decide on whether or how to use a certain technology can lead to information overload, which can result in greater reliance on heuristics and greater susceptibility to biases. In fact, many studies already showed the influence of cognitive biases on erroneous decisions in other fields (e.g., aviation accidents [54]). Assessment tools have been applied to reduce shortcomings and to improve quality 
[e.g., 64]. Bearing in mind those related findings and guidelines, we focus on the healthcare domain due to its high vulnerability to human failure. Since physicians' errors can be fatal and costly [39, 32, 5, 34], we strive to understand and to improve decisions regarding whether or how to use a certain technology in that occupation.

We will focus on the occurrence of overconfidence, because it is considered one of the cornerstones that illustrate shortcomings in human informationprocessing capacities, thereby marking human irrationality. It is associated with diagnostic inaccuracies or suboptimal management [49] and correlates with an underestimation of risk factors and tolerance to ambiguity [45]. Thus, understanding the impact of overconfidence on a physician's decisions is a promising path illustrating how behavioral economics and IS research can travel together.

As literature leads to the assumption that overconfidence might be a crucial cause of medical errors, which occurs in the form of biased calibration, biased precision of numerical estimates, and biased placement of performance, we pose the following research questions (RQs):

RQ1: How does overconfidence affect the accurate adoption and use of technology by physicians?

RQ2: How does overconfidence affect the medical errors made by physicians?

Seeing the cognitive bias of overconfidence as an important area of interest when it comes to why and how physicians use technology, our work has four objectives: 1) to highlight the value to consider cognitive biases in the healthcare domain, 2) to show the benefits of linking technology adoption and use of physicians to overconfidence, 3) to present a research agenda on how to evaluate the influence of overconfidence on prevention, diagnosis, treatment, and rehabilitation, and 4) to guide future research. It is important to note that our paper thereby focuses on exceptions of daily medical practice, namely the times when cognitive processes fail while using technology, which implies that a medical action is missed or wrong. We expect that physicians have a high confidence in their technology use behavior, which leads to underappreciating the chance of medical errors due to inappropriate usage.

The overall goal is both to highlight the practical implications of our findings to derive valuable recommendation for medical practice. Moreover, our work strives for understanding the impact of overconfidence on medical technological decisions to offer a theoretical contribution to advance the field.

\section{Theoretical background}

In our outline, the physicians' technology adoption and use cover the whole band width of health technology and can easily be itemized into specific application scenarios (e.g., adoption and use of telemedicine or artificial intelligence software).

\subsection{Cognitive biases in the healthcare domain}

According to the paradigm of rational choice, people decide and act based on thorough cost-benefit analysis to maximize profits. The prerequisites for rational choices are that people 1) know exactly what they want and prioritize, 2) have a set of alternative courses of action, and 3) know the likelihood of the events which they include in their calculation of costs and benefits $[62,15]$. It quickly becomes clear that this approach has a number of shortcomings and does not correspond properly to 'real' life. The most fundamental drawback is that no human knows everything, nor has s/he ideal mathematical methods. Homo sapiens, in contrast to Homo oeconomicus (aka Humans in contrast to Econs [57]), is unable to accurately identify all characteristics needed for an optimal decision. And even if s/he could: Calculating complex situations would take too long to make sense in an efficient manner. Knowledge deficits as well as restrictions in time and cognitive resources limit truly rational decision and action.

This leads to the concept of bounded rationality. According to the paradigm of rational choice, a suboptimal calculation of costs and benefits is seen as irrational and obstructive for the realization of human goals [45]. However, the decision-theorist Herbert Simon (Nobel Prize 1978) was a pioneer to assume that choices are naturally bounded by a number of factors [e.g., 50, 51]. For instance, humans consider only few alternatives; usually only two (which he termed 'satisficing'). Moreover, they tend to value things they own more highly than the things they could achieve by changing action ('endowment effect'). In addition, they tend to continue previous behavior even at considerable costs ('status quo bias'). Having named just a few examples, it becomes clear that humans are happy with reasonably satisfactory solutions, even if there is a good chance that there is a much more favorable option [see for further insights 4, 60, 10, 21].

So how do humans actually decide? Are humans bounded in the sense that they can no longer effectively choose what to do? Gigerenzer and his colleagues negate this attitude and assume that the rational consideration of all relevant factors at hand often brings no advantage [22, 19]. In many situations, 
heuristic decision-making, based on a very narrow information base and following simple rules, is just as or almost as efficient as complex arithmetic operations - but much faster and cheaper. Heuristics focus on a few salient features that can be used to decide between alternatives. One of the most common heuristics is the awareness of past experiences (for instance due to 'framing' or 'anchoring'). Humans rate the popularity of things by how easily concerning information is retrievable from their memory ('availability' heuristic). Simple and fast procedures often prevail.

However, simplistic rules of thumb do not always bring benefits. Literature demonstrates severe cognitive limitations when it comes to complex decisions (e.g., decision-making in the healthcare domain). Human behavior in complex systems falls short in particular by: 1) starting without sufficient prior analysis of the situation, 2) disregarding the positive and negative influences of most factors and measures, 3) focusing on immediate events while ignoring long-term and side effects, 4) the rigid belief to have the right method, 5) fleeing into new projects when things are about to go wrong or 6) taking more and more radical measures when things get out of hand [14]. This lesson is highly relevant to the healthcare domain. In particular, the physicians' belief to have the 'right' method (i.e., 'overconfidence') seems untenable against the background of the prevalence of biases.

IS research acknowledged the relevance of human cognition and decision-making biases related to information systems $[16,23]$. By providing a review of cognitive bias-related research in the IS discipline, Fleischmann et al. [16] revealed that the literature in this domain mainly concentrated on perception and decision biases (ibid.). They invited future research to be more diverse. Our work travels well with their idea to focus on action-oriented biases (e.g., 'overconfidence').

To sum up, many studies show the influence of cognitive biases on decision-making and provide valuable insights for the progress of our study. Although many cognitive biases serve an adaptive purpose as they allow to make sense of the world more quickly, they often outplay well-considered, but timeconsuming, decisions. The fact that there are various sensitive issues where an elaborate analysis and decision-making is required [such as choosing whether or how to use a certain technology for diagnosis or treatment, see e.g., 20], is a fruitful start to study the accuracy of physicians' technology adoption and use.

\subsection{Overconfidence in the healthcare domain}

Based on a structured review by Saposnik and his colleagues [49], common cognitive biases associated with medical decisions are based on perception biases (such as 'framing' [e.g., 44, see also 7]) or stability biases (such as 'anchoring' [e.g., 52, see also 1]). Approaches considering action-oriented biases (such as 'overconfidence') were also considered (c.f. Table 1). Action-orientated biases are a distinct subgroup within the category of decision biases [16]. Because premature decisions based on optimism without considering all relevant information are pressingly relevant for physicians as well, this paper seeks to further integrate action-oriented biases into the current debate.

Overconfidence is considered one of the cornerstones that illustrate shortcomings in human information-processing capacities, thereby marking human irrationality. It occurs in case our reliance related to judgments, inferences, or predictions is too high when compared to the corresponding accuracy [45]. Overconfidence is associated with diagnostic inaccuracies or suboptimal management [49] and leads to overestimation, over-precision, and over-placement [40]. Additionally, it correlates with an underestimation of risk factors and a high tolerance to ambiguity. Table 1 sums up general findings on overconfidence, which are relevant for our work.

\section{Table 1: Preliminary literature on}

\section{overconfidence}

\begin{tabular}{|l|l|l|}
\hline $\begin{array}{l}\text { Author (Year of } \\
\text { Publication) }\end{array}$ & Title & Source \\
\hline Keren (1997) & $\begin{array}{l}\text { "On the calibration of } \\
\text { probability } \\
\text { judgments: Some } \\
\text { critical comments } \\
\text { and alternative } \\
\text { perspectives" }\end{array}$ & {$[31]$} \\
\hline $\begin{array}{l}\text { Klayman et al. } \\
\text { (1999) }\end{array}$ & $\begin{array}{l}\text { "Overconfidence: It } \\
\text { depends on how, } \\
\text { what, and whom you } \\
\text { ask" }\end{array}$ & {$[33]$} \\
\hline $\begin{array}{l}\text { McGraw et al. } \\
\text { (2004) }\end{array}$ & $\begin{array}{l}\text { "The affective costs } \\
\text { of overconfidence" }\end{array}$ & {$[37]$} \\
\hline $\begin{array}{l}\text { Moore and Healy } \\
\text { (2008) }\end{array}$ & $\begin{array}{l}\text { "The trouble with } \\
\text { overconfidence" }\end{array}$ & {$[40]$} \\
\hline $\begin{array}{l}\text { Nandedkar and } \\
\text { Midha (2009) }\end{array}$ & $\begin{array}{l}\text { "Optimism in music } \\
\text { piracy: A pilot study" }\end{array}$ & {$[42]$} \\
\hline Rhee et al. (2005) & $\begin{array}{l}\text { "I am fine but you } \\
\text { are not: Optimistic } \\
\text { bias and illusion of } \\
\text { control on } \\
\text { information security" }\end{array}$ & $\begin{array}{l}\text { [47] } \\
\text { oxplains wecision } \\
\text { overconfidence } \\
\text { bias?" }\end{array}$ \\
\hline Tan et al. (2012) & $\begin{array}{l}\text { "Consumer-based } \\
\text { explain aid that }\end{array}$ & \\
\hline
\end{tabular}




\begin{tabular}{|l|l|l|}
\hline $\begin{array}{l}\text { Van der Vyver } \\
\text { (2004) }\end{array}$ & $\begin{array}{l}\text { "The overconfidence } \\
\text { effect and IT } \\
\text { professionals" }\end{array}$ & [59] \\
\hline $\begin{array}{l}\text { Vetter et al. } \\
(2011)\end{array}$ & $\begin{array}{l}\text { "Overconfidence in } \\
\text { IT investment } \\
\text { decisions: Why } \\
\text { knowledge can be a } \\
\text { boon and bane at the } \\
\text { same time" }\end{array}$ & [61] \\
\hline
\end{tabular}

The three most typical forms of overconfidence are “(1) calibration, (2) the precision of numerical estimates, and (3) people's placement of their own performance relative to others" [45:291]. They point at the fact that the subjective confidence exceeds objective accuracy, the subjective confidence intervals are too narrow, and people tend to better-than-average estimations of their own contribution or skills relative to others. Subjective confidence is based on selfknowledge and helps make quick judgements, although objective quantities are unknown, unstructured or by other means rough [63]. Closely linked to overconfidence is the illusion of control as well as the stable individual trait of optimism [45].

Overconfidence is also of interest for IS research. The domain studied the bias's occurrence in many settings such as enterprise resource planning [e.g., 28], innovation management [e.g., 18], and performance [e.g., 41]. As technology use became ubiquitous in the healthcare domain, the number of studies concerning technology use for medical diagnoses and treatment began to rise. However, a comprehensive review of the available literature and current thinking related to these issues is missing in this discipline [16]. This hampers both theorizing and finding practical solution to improve the accuracy of medical decision making while using technology.

Evidence suggests that the incidence of overconfidence is likely to be greater among top executives (ibid.). Physicians are without question seen as such experts who are ambitious, competent and obstinate. The benefits of overconfidence can be threefold for them [45:91 ff.]: First, it might have a consumption value of feeling good. People naturally enjoy receiving positive feedback, praise, and approval (also from thinking well of themselves). Second, it might have a motivation value. People with high confidence set high goals and persist in the face of adversary. Third, it might be a valuable signal for convincing others. Optimism about future events can positively affect those developments. A physician being overconfident about a particular treatment can be considered as the cause of a self-fulfilling prophecy or placebo effect. Against this background, it is of crucial importance to consider overconfidence, when the 'demigods in white' decide on whether or how to use a certain technology. Table 2 sums up recent findings on clinicians' overconfidence [see 49], also taking into account literature regarding the effect of overconfidence on medical errors.

Table 2: Preliminary literature and current findings on clinicians' overconfidence

\begin{tabular}{|c|c|c|}
\hline $\begin{array}{l}\text { Author (Year of } \\
\text { Publication) }\end{array}$ & Title & Source \\
\hline $\begin{array}{l}\text { Friedman et al. } \\
(2005)\end{array}$ & $\begin{array}{l}\text { "Are clinicians } \\
\text { correct when they } \\
\text { believe they are } \\
\text { correct? Implications } \\
\text { for medical } \\
\text { decision support" }\end{array}$ & [17] \\
\hline $\begin{array}{l}\text { Meyer et al. } \\
\text { (2013) }\end{array}$ & $\begin{array}{l}\text { "Physicians' } \\
\text { diagnostic } \\
\text { accuracy, confidence, } \\
\text { and resource } \\
\text { requests: a vignette } \\
\text { study" }\end{array}$ & [38] \\
\hline $\begin{array}{l}\text { Crowley et al. } \\
(2013)\end{array}$ & $\begin{array}{l}\text { "Automated } \\
\text { detection of } \\
\text { heuristics and biases } \\
\text { among pathologists } \\
\text { in a computer-based } \\
\text { system" }\end{array}$ & [12] \\
\hline $\begin{array}{l}\text { Saposnik et al. } \\
\text { (2013) }\end{array}$ & $\begin{array}{l}\text { "Accuracy of } \\
\text { clinician vs risk score } \\
\text { prediction of } \\
\text { ischemic stroke } \\
\text { outcomes" }\end{array}$ & [48] \\
\hline $\begin{array}{l}\text { Stiegler et al. } \\
(2012)\end{array}$ & $\begin{array}{l}\text { "Decision-making } \\
\text { and safety in } \\
\text { anaesthesiology" }\end{array}$ & [53] \\
\hline $\begin{array}{l}\text { Ogdie et al. } \\
(2012)\end{array}$ & $\begin{array}{l}\text { "Seen through their } \\
\text { eyes: residents' } \\
\text { reflections on the } \\
\text { cognitive and } \\
\text { contextual } \\
\text { components of } \\
\text { diagnostic errors in } \\
\text { medicine" }\end{array}$ & [43] \\
\hline $\begin{array}{l}\text { Saposnik, et al. } \\
\text { (2016) }\end{array}$ & $\begin{array}{l}\text { "Cognitive biases } \\
\text { associated with } \\
\text { medical decisions: A } \\
\text { systematic review" }\end{array}$ & [49] \\
\hline
\end{tabular}

\section{Model development}

Based on the theoretical background, we developed a preliminary research model. Overconfidence is considered as the independent variable. On the one hand, we propose a relation between overconfidence and technology use and seek to answer RQ1. On the other hand, we want to find out how overconfidence affects medical errors made by physicians to answer 
RQ2. We integrate technology use as a moderating variable that affects the strength of the relationship between medical errors and overconfidence. It is expected to have an amplifying effect. We will test for the moderating relation in an analysis of variance, where it is represented by the interaction effect between the dependent variable and the factor variable.

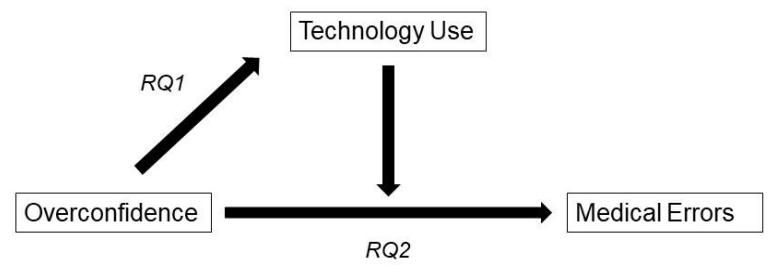

Figure 1: Model development

\section{Research design and data analysis}

Studying a complex decision in the healthcare domain offers tremendous potential. Because behavioral economic researchers rely mostly on experiments, it is a great opportunity to test their findings against other data [23]. As IS researchers have quite some knowledge in collecting and assembling observational datasets of technology adoption and use, these datasets provide a valuable source to fulfil this goal - also pointing at the potential of field experiments (e.g., in IT-mediated environments) to provide a middle ground between laboratories and observational data (ibid.). However, since there is no potential existing dataset to utilize, we propose a twostep mixed-methods approach to answer our RQs.

As noted above, physicians increasingly have many healthcare technologies at hand to decide whether or which one to use. Although there may be just one integrated healthcare information system for a hospital, especially resident physicians may have the luxury of multiple healthcare technologies. These can be various software, different possibilities for video consultation, sensor technology in medical devices or an integration of artificial intelligence (e.g., in the anamnesis of new patients). The multitude of technologies as well as their possible modes of operation is constantly increasing. Therefore, we do not want to commit to a specific technology in this work yet. However, the selection of a specific technology and a concrete application scenario is to be worked out in the proposed study directly at the beginning.

In a first step, we hand out a short survey to a group of physicians. We thereby want to answer RQ1 (How does overconfidence affect the accurate adoption and use of technology by physicians?). Table 3 provides initial questions regarding the proposed survey. Please note that actual objective answers are not available, but also not necessary, as the subjective answers illustrate a specific percentile of the entire reference population (e.g., top half) which makes the comparison of the percentage of people who believe they are in this percentile with the percentile itself meaningful.

Table 3: Sample questions for the later survey

\begin{tabular}{|c|c|}
\hline Concept & Selection of questions \\
\hline $\begin{array}{l}\text { Tolerance to technology- } \\
\text { related uncertainty } \\
{[46]}\end{array}$ & $\begin{array}{l}\text { It is fine for me that... } \\
\ldots \text { there are always new } \\
\text { developments in the } \\
\text { technologies we use. } \\
\text {...there are constant changes } \\
\text { in computer software. } \\
\text {...there are constant changes } \\
\text { in computer hardware. }\end{array}$ \\
\hline $\begin{array}{l}\text { Aversion to risk } \\
\text { [24] }\end{array}$ & $\begin{array}{l}\text { I am a cautious person who } \\
\text { generally avoids risk. } \\
\text { I am very willing to take } \\
\text { risks when choosing a job or } \\
\text { project to work on. } \\
\text { I usually play it safe, even if } \\
\text { it means occasionally losing } \\
\text { out on a good opportunity. }\end{array}$ \\
\hline $\begin{array}{l}\text { Confidence in the } \\
\text { appropriateness of } \\
\text { technology adoption and use } \\
\text { [adapted from 45] }\end{array}$ & $\begin{array}{l}\text { How high do you rate the } \\
\text { correctness of a patient's } \\
\text { medical history created by } \\
\text { artificial intelligence } \\
\text { software? } \\
\text { How likely is it that you } \\
\text { integrate this information } \\
\text { into your daily work } \\
\text { routine? }\end{array}$ \\
\hline $\begin{array}{l}\text { Confidence around } \\
\text { numerical estimates of } \\
\text { technology use } \\
\text { [adapted from 45] }\end{array}$ & $\begin{array}{l}\text { In which year will the first } \\
\text { fully electronic surgery take } \\
\text { place? }\end{array}$ \\
\hline $\begin{array}{l}\text { Placement on rankings } \\
\text { [adapted from 45] }\end{array}$ & $\begin{array}{l}\text { To what extent are you } \\
\text { taking advantage of } \\
\text { telemedicine opportunities } \\
\text { compared to your fellow } \\
\text { colleagues? } \\
\text { Do you think you finished } \\
\text { your final exam in the top } \\
\text { half of your class?' }\end{array}$ \\
\hline
\end{tabular}

The survey will be piloted with 50 respondents. Its items are adapted from the ones provided by Pohl [45]. Since our institute has a large network of doctors (outpatient and inpatient), we then aim to distribute the survey to at least 200 physicians of all disciplines. The specific discipline and the place of work (outpatient or inpatient) are controlled. First, we want to identify critical personality traits (e.g., tolerance to uncertainty, aversion to risk and ambiguity) and demographics. Second, we present questions pointing at overconfidence but disguise them as questions about general education and attitude (e.g., 'Do you think you 
finished your final exam in the top half of your class?'). Great exemplary questions are presented by Pohl and the collected authorship of his omnibus [45]. Because of the concealment, we will seek an ethical motion given by the University's ethics committee. Successively, we will inquire 1) the mean confidence in the appropriateness of technology adoption and use (e.g., (I) 'How high do you rate the correctness of a patient's medical history created by artificial intelligence software? (II) How likely is it that you integrate this information into your daily work routine?' (both questions rated on a Likert scale from $1-7))$, 2) the subjective confidence around numerical estimates of technology adoption and use (e.g., 'In which year will the first fully electronic surgery take place?'), 3) the mean subjective placement on rankings (e.g., 'To what extent are you taking advantage of telemedicine opportunities compared to your fellow colleagues?' (on a Likert scale from 1-7)). These findings provide us a picture of the overall overconfidence among physicians as we expect that the physicians' confidence on whether and how to use a certain technology exceeds objective accuracy, that their subjective confidence intervals are oftentimes too narrow, and that they tend to better-than-average estimations of their own contribution or skills relative to others.

In a second step, we chose a qualitative research design as we seek to understand and interpret events from the perspective of the physicians involved. We thereby want to answer RQ2 (How does overconfidence affect the medical errors made by physicians?). First, we present a short film (3 $\mathrm{min})$ about a typical treatment situation to each participant in which no medical mistakes are made. An interviewer discusses the presented situation in a semistructured manner and asks (subsequently implicitly and explicitly) about the occurrence of cognitive biases (e.g., overconfidence and illusion of control). Second, we present a short film $(3 \mathrm{~min})$ to the same person about an atypical treatment situation in which a medical mistake is made. Again, the interviewer discusses the presented situation and asks (subsequently implicitly and explicitly) about the occurrence of cognitive biases (e.g., overconfidence and illusion of control). Then, the physicians are thanked and debriefed. The interviews are seen as beneficial to understand how overconfidence can impact medical errors, focusing on the individual cognitive processes of each particular physician. We identified a selection of exemplary questions concerning our proposed scenarios (c.f. Table 4).
Table 4: Sample questions for the later interview guide

\begin{tabular}{|c|c|}
\hline Concept & Selection of questions \\
\hline $\begin{array}{l}\text { Overconfidence } \\
\text { [among others adapted from } \\
38 \text { ] }\end{array}$ & $\begin{array}{l}\text { How would you rate the } \\
\text { likelihood of committing a } \\
\text { medical error in this } \\
\text { situation? } \\
\text { How much would you rely } \\
\text { on the presented technology } \\
\text { when treating this patient? } \\
\text { How would you rate the } \\
\text { amount of risk factors? } \\
\text { Do you feel that this } \\
\text { situation is ambiguous? }\end{array}$ \\
\hline $\begin{array}{l}\text { Optimism } \\
\text { [adapted from 26] }\end{array}$ & $\begin{array}{l}\text { In this situation, ... } \\
\text {...the use of technology is } \\
\text { enhancing our standard of } \\
\text { treatment. } \\
\text {...treatment will be easier } \\
\text { and faster with technology. } \\
\text {..technology is a fast and } \\
\text { efficient means of getting } \\
\text { information. } \\
\text {...technology can eliminate } \\
\text { a lot of tedious work. }\end{array}$ \\
\hline $\begin{array}{l}\text { Illusion of control } \\
\text { [adapted from 29] }\end{array}$ & $\begin{array}{l}\text { How would you rate the } \\
\text { amount of control you have } \\
\text { over this work situation? } \\
\text { How would you rate the } \\
\text { amount of control you have } \\
\text { over your contribution to the } \\
\text { well-being of this patient? }\end{array}$ \\
\hline
\end{tabular}

The quantitative part of the study is analyzed using empirical social research methods. On the one hand, a confirmatory factor analysis is conducted to check whether the three expected subcategories of overconfidence (i.e. calibration, precision of numerical estimates, placement of performance) are reflected in the data. The relationships are further studied by executing univariate and multivariate regression analysis. Next, the qualitative part of the study will be audibly recorded and transcribed. The analysis consists of the identification of analysis units and the definition and coding of structured dimensions. The transcripts are interpreted independently by two researchers and finally checked for intercoder reliability. The analysis phase closes with a quantitative evaluation, a final interpretation, and a derivation of recommendations for actions from the analysis units.

Figure 2 shows the proposed research agenda, the related RQ for each step and the sample as well as sample size. The first sample covers the physicians in the pilot test. The second sample encompasses the physicians in the actual survey. 


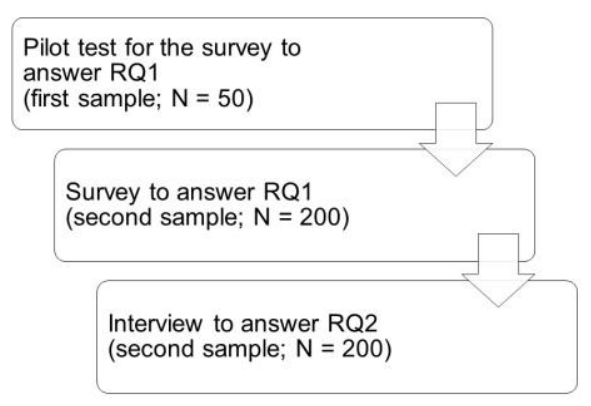

Figure 2: Research agenda

We keep in mind that overconfidence might depend on the sampling procedure and how performance is assessed [45]. Besides, the sampling procedure can be confounded with item difficulty and overconfidence can co-vary with item difficulty. Besides these potential limitations, the advantage of our mixedmethod study is that it provides a complete picture of the particularities of overconfidence and assumptions about the underlying mechanisms of technology adoption and use. The design is well suited to explain the physicians' reality. It takes advantage of both methodological approaches and minimizes associated pitfalls. As a result, the qualitative results can be statistically generalized and the relevance and replicability of the quantitative findings can be increased.

\section{Concluding remarks on how to beat cognitive biases by design}

Against the background that the healthcare domain faces major changes and challenges, questions arise on whether physicians are able to effectively decide which technologies to use in which setting and whether their technology use subsequently enhances treatment quality and thus patient safety. Literature on cognitive biases broadly looked at errors in judgment and decision-making, while questioning rational behavior. However, overconfidence, being one of the most common cognitive biases, has barely been linked to the accurate adoption and use of technology by physicians. We proposed a mixed-methods study based on the particularities of overconfidence. The study's main aims are to provide new insights that may affect patient outcomes (e.g., avoidable hospitalizations, complications related to a procedure, prevention of unnecessary tests or medication, etc.) and to help attenuate medical errors. To stress the importance of these aims, we briefly address the implications of our work.
Theoretical implications. In order to provide a holistic view on the IS domain, we invite future research to further compare our findings with established theoretical frameworks in IS research (e.g., theory of planned behavior). This can also mean adding further variables to the model (e.g., perceived ease of use, perceived usefulness). Since most literature about technology adoption and use is based on the rational choice paradigm, our investigation has the potential to question and test human decisionmaking and judgement. In addition, there is a chance that IS research and behavioral economics research travel together and learn from one another. Moreover, a theoretical direction is that the effects of biases can be manipulated by nudging humans in directions that will make their lives better and easier [58]. Thus, the nudge paradigm is seen as very promising in the healthcare domain, too, and opens the door for further question on the physicians' technology adoption and use. Digital health solutions that incorporate nudges [e.g., interactive text-message reminders or haptic medication alerts, see 56] might create innovative pathways and can be studied as use cases.

Implications for practice and design. As an outcome of our research, it can be discussed how technology can be designed to reduce overconfidence of physicians. Thus, future research can promote direct insights into how to design technologies for everyday medical practice to reduce medical errors. Future quantitative studies can objectify and embed these results. On top of that, future work is invited to review existing tools to reduce the occurrence of cognitive biases (e.g., checklists, cognitive calibration) to provide further recommendation on how to reduce overconfidence. When it comes to training and education for physicians, one can also think of new digital technologies such as augmented reality and virtual reality, which have a demonstrably positive effect on learning success. Since effective educational strategies are needed to overcome the effect of cognitive biases on medical judgement and decisionmaking when adapting and using technology, prospective studies evaluating and comparing different training strategies are highly valuable.

\section{References}

[1] Allen, G., and J. Parsons, "Is Query Reuse Potentially Harmful? Anchoring and Adjustment in Adapting Existing Database Queries", Information Systems Research 21(1), 2010, pp. 56-77.

[2] Ariely, D., Predictably Irrational: The Hidden Forces that Shape our Decisions, Harper, New York, NY, 2008. 
[3] Baron, J., Thinking and Deciding, Cambridge University Press, New York, 2008.

[4] Becker, G.S., "Irrational Behavior and Economic Theory", Journal of Political Economy 70(1), 1962, pp. 113 .

[5] van den Berge, K., and S. Mamede, "Cognitive Diagnostic Error in Internal Medicine", European Journal of Internal Medicine 24(6), 2013, pp. 525-529.

[6] Centers for Disease Control and Prevention, "Up to 40 Percent of Annual Deaths from Each of Five Leading US Causes are Preventable", Premature deaths from each cause due to modifiable risks, 2014.

https://www.cdc.gov/media/releases/2014/p0501preventable-deaths.html

[7] Cheng, F.-F., and C.-S. Wu, "Debiasing the Framing Effect: The Effect of Warning and Involvement", Decis. Support Syst. 49(3), 2010, pp. 328-334.

[8] Classen, D.C., S.L. Pestotnik, R.S. Evans, and J.P. Burke, "Computerized Surveillance of Adverse Drug Events in Hospital Patients”, JAMA 266(20), 1991, pp. 2847-2851.

[9] Committee on Quality of Health Care in America, Crossing the Quality Chasm: A New Health System for the 21st Century, National Academies Press, Institute of Medicine, Washington D.C., 2001.

[10] Cook, K.S., and M. Levi, The Limits of Rationality, University of Chicago Press, 2008.

[11] Croskerry, P., "The Importance of Cognitive Errors in Diagnosis and Strategies to Minimize Them", Academic Medicine 78(8), 2003, pp. 775.

[12] Crowley, R.S., E. Legowski, O. Medvedeva, et al., "Automated Detection of Heuristics and Biases among Pathologists in a Computer-based System", Advances in Health Sciences Education: Theory and Practice 18(3), 2013, pp. 343-363.

[13] Dimoka, A., F.D. Davis, A. Gupta, et al., "On the Use of Neurophysiological Tools in IS Research: Developing a Research Agenda forNeuroIS", MIS Quarterly 36(3), 2012, pp. 679-702.

[14] Dörner, D., Die Logik des Misslingens: Strategisches Denken in komplexen Situationen, Rowohlt Verlag GmbH, 2011.

[15] Esser, H., Soziologie. Spezielle Grundlagen. Band 1: Situationslogik und Handeln, Campus Verlag, Frankfurt/Main, 2002.

[16] Fleischmann, M., M. Amirpur, A. Benlian, and T. Hess, "Cognitive biases in information systems research: A scientometric analysis", Proceedings of the European Conference on Information Systems (ECIS), (2014).

[17] Friedman, C., G. Gatti, A. Elstein, T. Franz, G. Murphy, and F. Wolf, "Are clinicians correct when they believe they are correct? Implications for medical decision support", Studies in health technology and informatics(1), 2001, pp. 454-458.

[18] Galasso, A., and T.S. Simcoe, "CEO Overconfidence and Innovation”, Management Science 57(8), 2011, pp. 1469-1484.

[19] Gigerenzer, G., Adaptive Thinking: Rationality in the Real World, Oxford University Press, Oxford, 2002.

[20] Gigerenzer, G., Das Einmaleins der Skepsis: Über den richtigen Umgang mit Zahlen und Risiken, eBook Berlin Verlag, Berlin, 2014.

[21] Gigerenzer, G., and R. Selten, Bounded Rationality: The Adaptive Toolbox, MIT Press, Cambridge, 2002.

[22] Gigerenzer, G., P.M. Todd, and A.R. Group, Simple Heuristics that Make Us Smart, Oxford University Press, Oxford, 2000.

[23] Goes, P.B., “Editor's Comments: Information Systems Research and Behavioral Economics", MIS Q. 37(3), 2013, pp. iii-viii.

[24] Gray, P.H., and A. Durcikova, "The Role of Knowledge Repositories in Technical Support Environments: Speed Versus Learning in User Performance", Journal of management Information Systems 22(3), 2005, pp. 159-190.

[25] Greifeneder, R., H. Bless, and K. Fiedler, Social Cognition: How Individuals Construct Social Reality, Psychology Press, London, 2017.

[26] Harrison, A.W., and R.K. Rainer, "The Influence of Individual Differences on Skill in End-User Computing", Journal of management Information Systems 9(1), 1992, pp. 93-111.

[27] Haselton, M.G., D. Nettle, and D.R. Murray, "The Evolution of Cognitive Bias", In Handbook of Evolutionary Psychology. John Wiley \& Sons, Hoboken, NJ, USA, 2016, 968-987.

[28] Hunton, J.E., A.M. Wright, and S. Wright, “Are Financial Auditors Overconfident in Their Ability to Assess Risks Associated with Enterprise Resource Planning Systems?", Journal of Information Systems, 2004, pp. 22.

[29] Johnson, W., and R.F. Krueger, "How Money Buys Happiness: Genetic and Environmental Processes Linking Finances and Life Satisfaction", Journal of Personality and Social Psychology 90(4), 2006, pp. 680-691. 
[30] Kahneman, D., and A. Tversky, "Subjective Probability: A Judgment of Representativeness", Cognitive Psychology 3(3), 1972, pp. 430-454.

[31] Keren, G., "On The Calibration of Probability Judgments: Some Critical Comments and Alternative Perspectives", Journal of Behavioral Decision Making 10(3), 1997, pp. 269-278.

[32] Khoo, E.M., W.K. Lee, S. Sararaks, et al., "Medical Errors in Primary Care Clinics: A Cross Sectional Study", BMC family practice 13, 2012, pp. 127.

[33] Klayman, J., J.B. Soll, C. González-Vallejo, and S. Barlas, "Overconfidence: It Depends on How, What, and Whom You Ask", Organizational Behavior and Human Decision Processes 79(3), 1999, pp. 216-247.

[34] Mamede, S., T. van Gog, K. van den Berge, J.L.C.M. van Saase, and H.G. Schmidt, "Why do Doctors Make Mistakes? A Study of the Role of Salient Distracting Clinical Features", Academic Medicine: Journal of the Association of American Medical Colleges 89(1), 2014, pp. 114-120.

[35] Marmot, M., "Social Determinants of Health Inequalities", Lancet Public Health 365, 2005, pp. 10991104.

[36] Marmot, M., J. Allen, R. Bell, E. Bloomer, and P. Goldblatt, "WHO European Review of Social Determinants of Health and the Health Divide", The Lancet 380, 2012, pp. 1011-1029.

[37] McGraw, A.P., B.A. Mellers, and I. Ritov, "The affective costs of overconfidence", Journal of Behavioral Decision Making 17(4), 2004, pp. 281-295.

[38] Meyer, A.N., V.L. Payne, D.W. Meeks, R. Rao, and H. Singh, "Physicians' diagnostic accuracy, confidence, and resource requests: a vignette study", JAMA internal medicine 173(21), 2013, pp. 1952-1958.

[39] Michaels, A.D., S.A. Spinler, B. Leeper, et al., "Medication Errors in Acute Cardiovascular and Stroke Patients: A Scientific Statement from the American Heart Association", Circulation 121(14), 2010, pp. 1664-1682.

[40] Moore, D.A., and P.J. Healy, "The trouble with overconfidence.", Psychological Review 115(2), 2008, pp. 502-517.

[41] Moores, T.T., and J.C.-J. Chang, "Self-efficacy, overconfidence, and the negative effect on subsequent performance: A field study", Information \& Management 46(2), 2009, pp. 69-76.

[42] Nandedkar, A., and V. Midha, "Optimism in Music Piracy: A Pilot Study", Proceedings of the Thirtieth International Conference on Information Systems, (2009).
[43] Ogdie, A.R., J.B. Reilly, M.W.G. Pang, et al., "Seen through their eyes: residents' reflections on the cognitive and contextual components of diagnostic errors in medicine", Academic medicine: journal of the Association of American Medical Colleges 87(10), 2012, pp. 1361.

[44] Perneger, T.V., and T. Agoritsas, "Doctors and patients' susceptibility to framing bias: a randomized trial", Journal of General Internal Medicine 26(12), 2011, pp. 1411-1417.

[45] Pohl, R.F., Cognitive Illusions: A Handbook on Fallacies and Biases in Thinking, Judgement and Memory, Psychology Press, London, 2004.

[46] Ragu-Nathan, T.S., M. Tarafdar, B.S. Ragu-Nathan, and $\mathrm{Q} . \mathrm{Tu}$, "The consequences of technostress for end users in organizations: Conceptual development and empirical validation", Information Systems Research 19(4), 2008, pp. 417-433.

[47] Rhee, H.-S., Y. Ryu, and C.-T. Kim, "I Am Fine but You Are Not: Optimistic Bias and Illusion of Control on Information Security", Proceedings of the Twenty-Sixth International Conference on Information Systems, (2005).

[48] Saposnik, G., R. Cote, M. Mamdani, et al., "JURaSSiC: accuracy of clinician vs risk score prediction of ischemic stroke outcomes", Neurology 81(5), 2013, pp. 448-455.

[49] Saposnik, G., D. Redelmeier, C.C. Ruff, and P.N. Tobler, "Cognitive Biases Associated with Medical Decisions: a Systematic Review", BMC Medical Informatics and Decision Making 16(1), 2016.

[50] Simon, H.A., "Rational Decision Making in Business Organizations", The American Economic Review 69(4), 1979, pp. 493-513.

[51] Simon, H.A., "Bounded Rationality", In J. Eatwell, M. Milgate and P. Newman, eds., Utility and Probability. Palgrave Macmillan UK, London, 1990, 15-18.

[52] Sorum, P.C., J. Shim, G. Chasseigne, S. Bonnin-Scaon, J. Cogneau, and E. Mullet, "Why do primary care physicians in the United States and France order prostate-specific antigen tests for asymptomatic patients?", Medical Decision Making: An International Journal of the Society for Medical Decision Making 23(4), 2003, pp. 301-313.

[53] Stiegler, M.P., and K.J. Ruskin, "Decision-making and Safety in Anesthesiology", Current Opinion in Anaesthesiology 25(6), 2012, pp. 724-729.

[54] Stripe, S.C., L.G. Best, S. Cole-Harding, B. Fifield, and F. Talebdoost, "Aviation Model Cognitive Risk Factors Applied to Medical Malpractice Cases", Journal of the American Board of Family Medicine: JABFM 19(6), 2006, pp. 627-632. 
[55] Tan, W.-K., C.-H. Tan, and H.-H. Teo, “Consumerbased decision aid that explains which to buy: Decision confirmation or overconfidence bias?", Decision Support Systems 53(1), 2012, pp. 127-141.

[56] Textra Healthcare, LLC., "Textra Healthcare", TextConnect: Connecting Patients and Providers, 2019. http://textrahealthcare.com/

[57] Thaler, R.H., Misbehaving: The Making of Behavioural Economics, W W Norton \& Co., New York, 2015.

[58] Thaler, R.H., and C.R. Sunstein, Nudge: Improving Decisions About Health, Wealth and Happiness, Penguin, London, 2009.

[59] Van der Vyver, G., "The Overconfidence Effect and IT Professionals", Proceedings of the European Conference on Information Systems (ECIS), (2004).

[60] Vanberg, V.J., "The rationality postulate in economics: its ambiguity, its deficiency and its evolutionary alternative", Journal of Economic Methodology 11(1), 2004, pp. 1-29.
[61] Vetter, J., A. Benlian, and T. Hess, "Overconfidence in IT Investment Decisions: Why Knowledge can be a Boon and Bane at the same Time", Proceedings of Thirty-Second International Conference on Information Systems, (2011),

17.

[62] Weber, M., Gesammelte Aufsätze zur Wissenschaftslehre, J.C.B. Mohr, Tübingen, 1922.

[63] Winman, A., P. Hansson, and P. Juslin, "Subjective Probability Intervals: How to Reduce Overconfidence by Interval Evaluation", Journal of Experimental Psychology: Learning, Memory, and Cognition 30(6), 2004, pp. 11671175.

[64] Zeltser, M.V., and D.B. Nash, "Approaching the Evidence Basis for Aviation-derived Teamwork Training in Medicine", American Journal of Medical Quality: The Official Journal of the American College of Medical Quality 25(1), 2010, pp. 13-23. 